\title{
Role of Heme Oxygenase and Bilirubin in Oxidative Stress in Preterm Infants
}

\author{
CARLO DANI, EMANUELA MASINI, GIOVANNA BERTINI, ANNA MARIA DI FELICE, \\ MARCO PEZZATI, SILVIA CIOFINI, MAURO ROSSETTI, GABRIELE GALLORI, \\ RICCARDO CIUTI, GIUSEPPE BUONOCORE, PATRIZIA PAFFETTI, \\ PIER FRANCESCO MANNAIONI, AND FIRMINO F. RUBALTELLI
}

\author{
Department of Surgical and Medical Critical Care [C.D., G.B., M.P., S.C., F.F.R.], Section of \\ Neonatology, Careggi University Hospital of Florence, Viale Morgagni, 85, 50134 Florence, Italy; \\ Department of Clinical and Preclinical Pharmacology [E.M., A.M.D.F., P.F.M.], Careggi University \\ Hospital of Florence, Viale Morgagni, 85, 50134 Florence, Italy; Central Laboratory of Chemical-Clinical \\ Analysis [M.R., G.G., R.C.], Careggi University Hospital of Florence, Viale Morgagni, 85, 50134 \\ Florence, Italy; and Department of Pediatrics [G.B., P.P.], Obstetrics and Reproductive Medicine, \\ University of Siena, Viale M. Bracci, 16, 53100 Siena, Italy
}

\begin{abstract}
In a previous study, it was found that the decrease in the total plasma bilirubin level (Btot) in preterm infants was associated with the decrease in oxidative stress. We hypothesized that this occurs as a result of a pro-oxidant effect of heme oxygenase (HO), which outcompetes with the antioxidant properties of bilirubin. In this study we studied 12 preterm infants in whom the plasma levels of Btot, total hydroperoxide (TH), protein $\mathrm{SH}$ groups, HO activity, non-transferrin-bound iron (NTBI), and erythrocyte $\mathrm{CuZn}$ superoxide dismutase (CuZn SOD) activity were concurrently measured when the Btot was $>220 \mu \mathrm{M}$ and after a Btot drop of $>34 \mu \mathrm{M}$. The Btot decrease was concurrent with the TH decrease, protein $\mathrm{SH}$ groups increase, and the HO and $\mathrm{CuZn}$ SOD activity increase and was not associated with an NTBI increase. We concluded that 1) Btot does not exert a
\end{abstract}

\section{ABSTRACT}

meaningful antioxidant effect in vivo; 2) $\mathrm{HO}$ does not exert a pro-oxidant effect involving an NTBI increase and that, on the contrary, it could exert an antioxidant effect; and 3) the concurrent $\mathrm{HO}$ and $\mathrm{CuZn}$ SOD activity increase could indicate a synergic antioxidant effect of the two enzymes. (Pediatr Res 56: 873-877, 2004)

$\quad$ Abbreviations
Btot, total bilirubin plasma level
CuZn SOD, CuZn superoxide dismutase
HO, heme oxygenase
NTBI, non-transferrin-bound iron
TH, total hydroperoxide

Many illnesses in preterm infants, including chronic lung disease, necrotizing enterocolitis, retinopathy of prematurity, and intracranial hemorrhage, are thought to be related to the action of reactive oxygen species. This presumably occurs because the antioxidant system of preterm infants is at the same time highly stressed and incompletely developed (1). Moreover, it is well known that during the first days of life, the catabolism of fetal $\mathrm{Hb}$ results in a tissue burden of heme that is a potentially pro-oxidant damaging molecule that not only provides a lipophilic form of iron but can itself directly attack the lipid bilayer, the cytoskeleton, and DNA (2,3). Several reports have emphasized the antioxidant role of bilirubin, which in human neonatal plasma seems to have a greater

Received November 27, 2003; accepted June 8, 2004

Correspondence: Carlo Dani, M.D., Division of Neonatology, Careggi University Hospital, University of Florence School of Medicine, Viale Morgagni, 85, 50134 Firenze, Italy; e-mail: cddni@.unifi.it

DOI: 10.1203/01.PDR.0000145281.12853.9E antioxidant potency than urates, $\alpha$-tocopherol, or ascorbates (4). Nevertheless, although the antioxidant effect of bilirubin as a scavenger of reactive oxygen species is well documented in vitro (5-8) as well as in animal studies (9), its role in vivo has not been definitively clarified in preterm infants (10-13). Even less is known about the role of heme oxygenase (HO) in oxidative stress of the newborn infant. Heme oxygenase is the enzyme responsible for physiologic heme degradation into equimolar amounts of $\mathrm{CO}$ and biliverdin and the release of free iron (14). It has been suggested that its inducible form, HO-1, might represent a generalized response to oxidative stress (15-17) and that HO-1 could confer cellular protection against oxidant stress $(14,18-20)$. However, recent studies suggest that HO-1 induction might not always be beneficial and that the release of redox-active iron from heme might induce enhance oxidative stress $(21,22)$.

In a previous study, we found that in jaundiced preterm infants, a decrease of bilirubin plasma level (Btot) was asso- 
ciated with an increase of plasma antioxidant capacity and a decrease of oxidative stress in preterm infants; this did not occur in a similar population of preterm infants who did not have jaundice and did not show changes of oxidant stress during the study period (23). To explain these results, we hypothesized that this occurs as a result of a pro-oxidant effect of HO-1, mediated by iron release, which could overcome the antioxidant properties of bilirubin. To evaluate this hypothesis, we carried out the present prospective study in which the plasma levels of Btot, total hydroperoxide $(\mathrm{TH})$, protein $\mathrm{SH}$ groups, $\mathrm{HO}$ activity, non-transferrin-bound iron (NTBI), and erythrocyte CuZn superoxide dismutase (CuZn SOD) activity were measured concurrently in a cohort of preterm infants.

\section{METHODS}

Patients. The study was conducted at the neonatal intensive care unit of Careggi University Hospital of Florence after approval by the Local Ethical Committee. After obtaining informed parental consent, we studied 12 healthy preterm infants who were enrolled consecutively in the study when they were $\leq 36$ wk gestational age, were $\leq 7 \mathrm{~d}$ of age, presented nonhemolytic hyperbilirubinemia requiring phototherapy, did not require respiratory support, were clinically stable, did not experience perinatal asphyxia or sepsis, and had no major congenital malformations. When parenteral nutrition was required, the solutions were protected from light and did not contain lipids and multivitamins to exclude the occurrence of oxidative stress from this source (24).

For each newborn infant, sex, gestational age, birth weight, type of delivery, Apgar score at $5 \mathrm{~min}$, antenatal steroid treatment, main pathologies, and pregnancy diseases were recorded. The Btot was measured in blood samples by reflectance spectrophotometry (Microbilimeter; Ginevri, Rome, Italy) at study entry and after the Btot dropped $>34 \mu \mathrm{mol} / \mathrm{L}$. The accuracy of Btot measurement in our unit was recently tested. and the correlation between our laboratory method and the HPLC Btot measurement was high ( $r=0.927 ; 95 \%$ confidence interval 0.906-0.944) (25).

At the same time, a blood heparinized sample was obtained to measure $\mathrm{TH}$, protein $\mathrm{SH}$ groups, $\mathrm{HO}$ activity, NTBI plasma level, and erythrocyte CuZn SOD. Erythrocyte CuZn SOD activity was evaluated to confirm indirectly the existence of oxidative stress in our patients because it is widely known that the expression and the activity of CuZn SOD are enhanced by oxidative stress (26).

The blood samples were obtained from the umbilical venous catheter when possible or from a peripheral vein. In the first case, infusion contamination was excluded by aspirating the infused solution and at least $0.5 \mathrm{~mL}$ of blood from the catheter before collecting blood for the analysis. Conventional phototherapy (Photo-Therapie 800; Drager, Lubeck, Germany) was initiated for a Btot value of $>220 \mu \mathrm{mol} / \mathrm{L}$ and was discontinued when Btot was $<170 \mu \mathrm{mol} / \mathrm{L}$.

Procedures. After centrifugation, the plasma and buffy coat were removed. The erythrocyte pellets were washed three times with $0.9 \% \mathrm{NaCl}$. The analyses of $\mathrm{TH}$ and protein $\mathrm{SH}$ groups were carried out in plasma within $2 \mathrm{~h}$ of blood sampling to avoid the effects of storage. The remaining samples of plasma and red blood cells were frozen at $-80^{\circ} \mathrm{C}$ for later analysis of $\mathrm{HO}$ and CuZn SOD activity and NTBI.

TH represents a measure of overall oxidative stress, given that it is the intermediate oxidative product of lipids, peptides, and amino acids. Its production was measured with a d-ROMs Kit (Diacron srl, Grosseto, Italy) by the method described by Buonocore et al. (27). The results were expressed in conventional units, called Carr units. The value of 1 Carr unit is equal to a concentration of $0.08 \mathrm{mg} / \mathrm{dL}$ of hydrogen peroxide. Protein SH groups were measured with a SHp Test (Diacron srl, Italy) using a spectrophotometric procedure in accordance with Ellman (28). For determining HO-1 activity, red blood cells were washed twice with $0.9 \% \mathrm{NaCl}$ and then homogenized and incubated for $30 \mathrm{~min}$ at $37^{\circ} \mathrm{C}$ with $50 \mu \mathrm{L}$ of rat liver biliverdin reductase $(0.21 \mu \mathrm{g}$ of protein in a volume of $100 \mu \mathrm{L})$ to convert biliverdin in bilirubin. The concentration of SH groups was expressed as $\mu \mathrm{mol} / \mathrm{L}$ of protein $\mathrm{SH}$ groups. The level of bilirubin was measured spectrophotometrically using a Sigma Chemical Co. Diagnostic Procedure (St. Louis, MO) and was expressed as nanograms of bilirubin formed per milligram of protein per hour. NTBI plasma levels were determined by HPLC using the method described by Kime et al. (29), partially modified, and were expressed as micromoles per liter. For measurement of CuZn SOD activity, Hb was removed from lysed erythrocytes, and the CuZn SOD activity was determined using a cytochrome $c$ assay (30) and expressed as units per gram of $\mathrm{Hb}$. The amount of CuZn SOD required to inhibit the rate of reduction of cytochrome $c$ by $50 \%$ was defined as a unit of activity.

Statistical analysis. In planning our study, we calculated that a sample size of at least 12 infants in each group was required to detect a significant correlation between a change of $30 \%$ in TH plasma concentration and a change of $50 \mu \mathrm{Mol} / \mathrm{L}$ in Btot, with $80 \%$ power at 0.05 level. The data were expressed as mean values $( \pm \mathrm{SD})$ and analyzed for statistically significant differences by ANOVA test for continuous variables. Simple regression analysis was used to assess the correlation among Btot, $\mathrm{HO}$ activity, CuZn SOD activity, TH, and protein $\mathrm{SH}$ groups.

\section{RESULTS}

Twelve infants, 7 boys and 5 girls, were enrolled consecutively in the study. The mean gestational age and birth weight of the neonates was $32.1( \pm 1.6)$ weeks and $1730( \pm 498) \mathrm{g}$, respectively. Apgar score was $7.2( \pm 1.8)$ at $1 \mathrm{~min}$ and 8.3 $( \pm 0.7)$ at $5 \mathrm{~min}$. Eight $(67 \%)$ infants were born by cesarean section, and nine $(75 \%)$ infants received antenatal steroid treatment. All patients received phototherapy for a mean duration of $2.6( \pm 1.5)$ days. Among the mothers, seven were affected by preeclampsia, one was affected by placental abruption, one was affected by placenta previa, and three presented as idiopathic preterm delivery. All of the neonates with hyperbilirubinemia were admitted with the diagnosis of prematurity, but two experienced transient tachypnea, two experienced symptomatic hypoglycemia during the first $2 \mathrm{~d}$ of life, and three developed moderate feeding intolerance. During the 
study period, four patients received parenteral nutrition that did not exceeded $50 \%$ of fluid intake.

Because of the small size of blood samples in two patients, it was not possible to determine protein $\mathrm{SH}$ groups and in two other patients, it was not possible to determine CuZn SOD activity. The first blood sample was drawn at $3.7 \pm 1.2 \mathrm{~d}$ of life and the second at $6.7 \pm 2.5 \mathrm{~d}$ of life, both during phototherapy. By design, the Btot level was higher $(p<0.0001)$ at study entry $(235.6 \pm 15.5 \mu \mathrm{M})$ than later $(162.1 \pm 18.9 \mu \mathrm{M})$, whereas TH decreased from an initial value of $170.9 \pm 53.9$ to $124.2 \pm 42.4 \mathrm{U}$. Carr/L $(p<0.05)$ and protein $\mathrm{SH}$ groups increased from $258.8 \pm 48.2$ to $316.7 \pm 44.2 \mu \mathrm{M}(p<0.05$; Table 1). Both HO-1 and CuZn SOD activity rose from $31.7 \pm$ 8.3 to $40.1 \pm 8.9 \mathrm{ng}$ bilirubin $\cdot \mathrm{mg}$ protein ${ }^{-} 1 \cdot \mathrm{h}^{-} 1(p<0.05)$ and from $1334 \pm 155.4$ to $1565.7 \pm 234.3 \mathrm{U} / \mathrm{g} \mathrm{Hb}(p<0.05)$, respectively (Table 1). Finally, NTBI was found only in three samples from two patients ( 0.55 and $0.9 \mu \mathrm{M}$ in the first patient and $0.25 \mu \mathrm{M}$ at study entry in the second patient); therefore,

Table 1. Changes of HO activity, CuZn SOD activity, and TH and protein SH groups plasma levels at study entry and after the drop of Btot

\begin{tabular}{lccc}
\hline & \multicolumn{3}{c}{ After drop } \\
& At study entry & of Btot & $p$ \\
\hline Btot $(\mu \mathrm{mol} / \mathrm{L})$ & $235.6 \pm 15.5$ & $162.1 \pm 18.9$ & $<0.0001$ \\
HO activity $($ ng bilirubin·mg & $31.7 \pm 8.3$ & $40.1 \pm 8.9$ & 0.042 \\
$\quad$ protein $\left.\cdot \mathrm{h}^{-1}\right)$ & & & \\
SOD $(\mathrm{U} / \mathrm{g} \mathrm{Hb})$ & $1334.0 \pm 155.4$ & $1565.7 \pm 234.3$ & 0.025 \\
TH $($ Carr units/L) & $170.9 \pm 53.9$ & $124.2 \pm 42.4$ & 0.045 \\
SH $(\mu \mathrm{mol} / \mathrm{L})$ & $258.8 \pm 48.2$ & $316.7 \pm 44.2$ & 0.017
\end{tabular}

Data are means $\pm \mathrm{SD}$. we did not include this biochemical parameter in statistical analysis.

The Btot did not correlate with HO activity $(r=-0.420, p$ $=0.065), \mathrm{CuZn}$ SOD activity $(r=-0.235, p=0.348), \mathrm{TH}(r$ $=0.382, p=0.097)$, or protein SH groups $(r=-0.537, p=$ 0.238 ) values. A statistically significant correlation was observed between HO-1 plasma activity and CuZn SOD plasma activity, TH, and protein $\mathrm{SH}$ groups; between CuZn SOD activity and $\mathrm{TH}$ and protein $\mathrm{SH}$ groups; and between $\mathrm{TH}$ and protein $\mathrm{SH}$ groups (Fig. 1).

\section{DISCUSSION}

This is the first study to investigate the role of Btot in association with that of HO-1 in oxidative stress in preterm infants. Our results showed a decrease of Btot concurrent with the decrease of oxidative stress in preterm infants, as indicated by the decrease of $\mathrm{TH}$ and the increase of protein $\mathrm{SH}$ groups. These results confirm the findings of our previous study (in which we demonstrated that the decrease of Btot was associated with a decrease of oxidative stress in preterm infants, whereas this did not occur in the control group of infants without hyperbilirubinemia) (23) and disagree with previous studies using in vitro (5-8) and animal models (9), both of which described the antioxidant properties of bilirubin. However, bilirubin was not always found effective as an antioxidant agent: Mireles et al. (8) demonstrated in vitro that a bilirubin concentration $>30 \mathrm{mg} / \mathrm{dL}$ is associated with an increase in protein oxidation; moreover, the infusion of $15 \mathrm{mg} / \mathrm{kg}$ of bilirubin in an animal model was not effective in preventing oxidative stress and pulmonary hypertension induced by group B Streptococcus (31). (a)

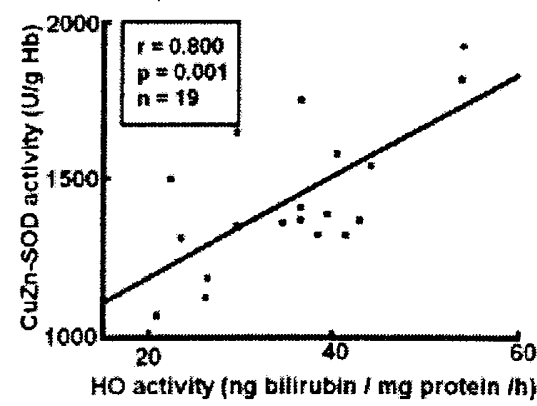

(b)

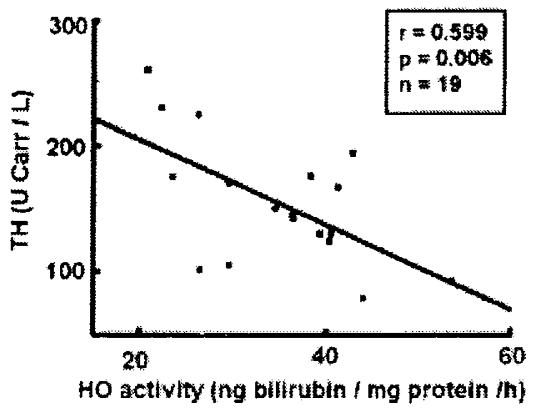

(c)

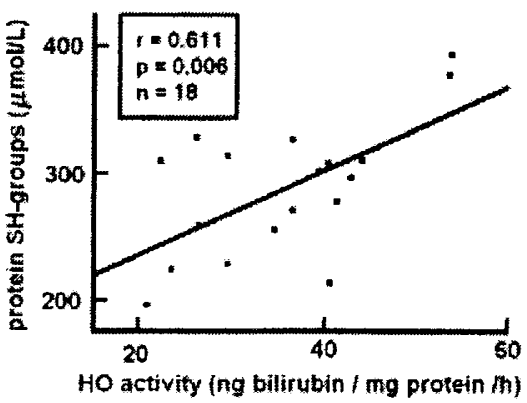

(d)

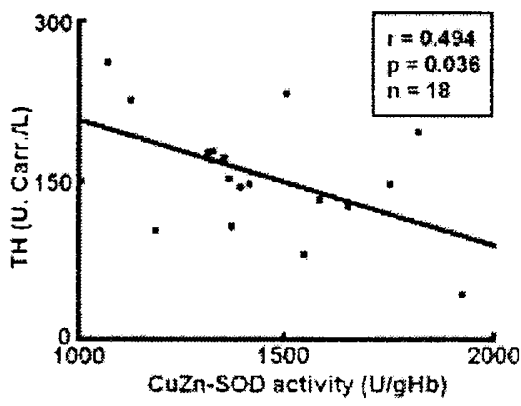

(ब)

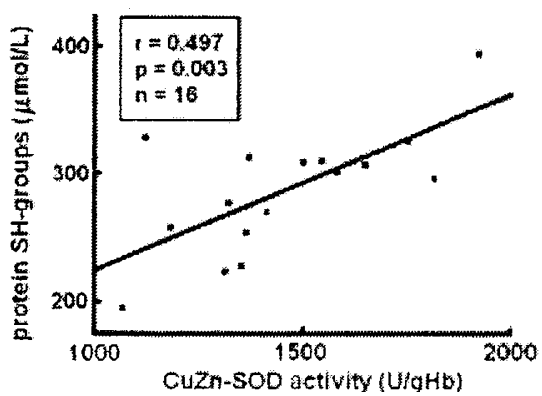

(f)

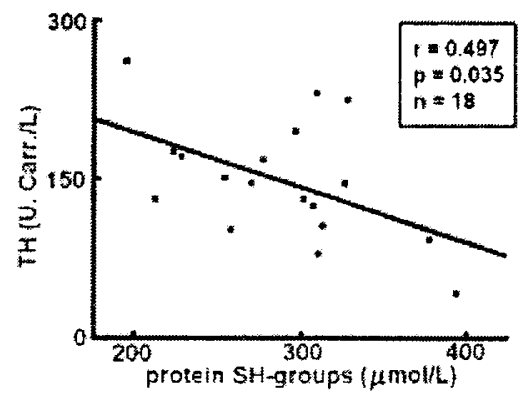

Figure 1. Correlation between $\mathrm{HO}$ and CuZn SOD activity (a), HO activity and TH plasma levels (b), HO activity and protein SH groups plasma levels (c), CuZn SOD activity and TH plasma levels $(d)$, CuZn SOD activity and protein SH groups plasma levels $(e)$, and TH and protein SH groups plasma levels $(f)$. 
Our results confirm the findings of Yigit et al. (10), who did not find a correlation between oxidative stress and Btot in preterm infants with nonhemolytic hyperbilirubinemia, and Gopinathan et al. (11), who did not observe a correlation between Btot and total plasma antioxidant capacity in preterm infants. However, Belanger et al. (12) found an association between reduction of the antioxidant capacity of plasma after exchange transfusion and the following decrease of Btot. This result, however, as indicated by the authors, could be explained by factors other than the bilirubin decrease, such as the oxidative stress induced by a large amount of transfused blood and the consequent overload of iron through the transfusion (21). Hammerman et al. (13) found a correlation between Btot and plasmatic antioxidant capacity, but the Btot of their patients was lower (mostly no more than $150 \mu \mathrm{M}$ ) than that reported in other studies $(10-12,23)$, and they did not specify how many patients underwent phototherapy. In fact, to partially explain these conflicting results, it is important to consider that the correlation between Btot and the antioxidant capacity of plasma could be different at low and high Btot and could be affected by phototherapy through its lowering effect on Btot, which, moreover, can explain the lack of correlation between bilirubin and $\mathrm{HO}$ activity.

The objective of our study was to determine whether the decrease of Btot associated with the decrease of oxidative stress in preterm infants might be explained by a pro-oxidant effect of HO-1, mediated by iron release. In fact, the role of HO-1 as pro-oxidant agent has been reported (32). Heme oxygenase is the enzyme responsible for physiologic heme degradation: it catalyzes the degradation of heme into equimolar amounts of $\mathrm{CO}$ and biliverdin, with the release of free iron (14). Three isoforms of $\mathrm{HO}$ have been isolated: inducible heme oxygenase (HO-1), constitutive heme oxygenase (HO-2), and the more recently discovered and less active heme oxygenase isoform (HO-3) (15). HO-1 is a known stress response protein, whose transcription can be induced by a whole array of stresses, including endotoxin, transition metals, heme, $\mathrm{Hb}$, and other heme proteins (32). Indeed, it has been suggested that HO-1 induction might represent a generalized response to oxidative stress $(15,16,33)$ and that it could confer cellular protection against oxidant stress $(14,18,20,34)$. However, recent studies suggest that HO-1 induction might not always be beneficial and that the release of redox-active iron from heme might induce an increase of oxidative stress $(21,35)$. Moreover, in vitro studies $(36,37)$ suggested that the possible protective antioxidant action of HO-1 could occur within a narrow range, as occurs when HO-1 is overexpressed, and free iron release may obviate any cytoprotective effect against oxidative stress (38).

In our patients, we demonstrated an increase of HO-1 activity in blood concurrent with the decrease of Btot and linearly correlated with the increase of CuZn SOD activity and the decrease of oxidative stress (represented by the decrease of TH and an increase of protein SH groups). These results and the lack of increase of NTBI exclude the hypothesis of a prooxidant effect of HO-1, which was based on the belief that the decrease of Btot was associated with a decrease of HO-1 activity. On the contrary, our data suggest an antioxidant effect of HO-1 that seems to be exerted in vivo by mechanisms other than bilirubin formation. These protective mechanisms could involve the removal of the pro-oxidant heme $(2,3)$, the removal of hydrogen superoxide during the degradation of heme (39), the induction of ferritin synthesis that sequesters redox-active iron $(38-40)$, and the regulation of superoxide anion production (41). Other possible mechanisms could involve the multiple ways by which $\mathrm{CO}$ modulates inflammatory processes, such as the reduction of neutrophil adhesion and extravasation (42), the reduction of histamine release from mast cells and human basophils $(43,44)$, inhibition of the expression of proinflammatory cytokines such as tumor necrosis factor- $\alpha$ and IL- $1 \beta$, and an increase of anti-inflammatory cytokine IL-10 (45).

In conclusion, we found that in our patients, the decrease of Btot was concurrent with the decrease of oxidative stress in preterm infants and with the increase of HO-1 and CuZn SOD activities and was not related to the increase of NTBI. This suggests that 1 ) Btot does not seem to exert a significant antioxidant effect in vivo despite displaying such activity in vitro; 2) HO-1 does not exert a pro-oxidant effect through an increase of NTBI and, on the contrary, could exert an antioxidant effect; and 3) the increase of HO-1 activity is correlated with the increase of CuZn SOD activity, suggesting a synergistic antioxidant action of the two enzymes.

\section{REFERENCES}

1. Thibeault DW 2000 The precarious antioxidant defenses of the preterm infant. Am J Perinatol 17:167-181

2. Tamion F, Richard V, Binmarchand G, Leroy J, Lebreton JP, Thuillez C 2001 Induction of heme oxygenase-1 prevents the systemic response to hemorrhagic shock. Am J Respir Crit Care Med 164:1933-1938

3. Dorè S 2002 Decreased activity of the antioxidant heme oxygenase enzyme: implications in ischemia and in Alzheimer's disease. Free Radic Biol Med 32:1276-1282

4. Miller NJ, Rice-Evans C, Davies MJ, Gopinathan V, Milner A 1993 A novel method for measuring antioxidant capacity and its application to monitoring the antioxidant status in premature neonates. Clin Sci (Lond) 84:407-412

5. Wu TW, Wu J, Li RK, Mickle D, Carey D 1991 Albumin-bounds bilirubins protect human ventricular myocytes oxyradical damage. Biochem Cell Biol 69:683-688

6. Stocker R, Glazer AN, Ames BN 1987 Antioxidant activity of albumin-bound bilirubin. Proc Natl Acad Sci U S A 84:5918-5922

7. Stocker R, Yamamoto Y, McDonagh AF, Glazer AN, Ames BN 1987 Bilirubin is an antioxidant of possible physiological importance. Science 235:1043-1046

8. Mireles LC, Lum MA, Dennery PA 1999 Antioxidant and cytotoxic effects of bilirubin on neonatal erythrocytes. Pediatr Res 45:355-362

9. Dennery PA, McDonagh AF, Spitz DR, Rogers PA, Stevenson DK 1995 Hyperbilirubinemia results reduced oxidative injury in neonatal Gunn rat exposed in hyperoxia. Free Radic Biol Med 19:395-404

10. Yigit S, Yurdakok M, Kilin K, Oran O, Erdem G, Tekinalp G 1999 Serum malondialdehyde concentrations in babies with hyperbilirubinemia. Arch Dis Child Fetal Neonatal Ed 80:F235-F237

11. Gopinathan V, Miller NJ, Milner AD, Rice-Evans CA 1994 Bilirubin and ascorbate antioxidant activity in neonatal plasma. FEBS Lett 349:197-200

12. Belanger S, Lavoie JC, Chessex P 1997 Influence of bilirubin on the antioxidant capacity of plasma in newborn infants. Biol Neonate 71:233-238

13. Hammerman C, Goldstein R, Kaplan M, Eran M, Goldschmidt D, Eidelman AI, Gartner LM 1998 Bilirubin in the premature: toxic waste or natural defense? Clin Chem 44:2551-2553

14. Elbirt KK, Bonkovsky HL 1999 Heme oxygenase: recent advances in understating its regulation and role. Proc Assoc Am Physicians 111:438-447

15. Keyse SM, Applegate LA, Tromvoukis Y, Tyrrell TM 1990 Oxidant stress leads to transcriptional activation of the human heme oxygenase gene in cultured skin fibroblasts. Mol Cell Biol 10:4967-4969

16. Vile GF, Basu-Modak S, Waltner C, Tyrrell RM 1994 Heme oxygenase 1 mediates an adaptive response to oxidative stress in human skin fibroblasts. Proc Natl Acad Sci U S A 91:2607-2610

17. Lautier D, Luscher P, Tyrrell RM 1992 Endogenous glutathione levels, modulate both constitutive and UVA radiation/hydrogen peroxide inducible expression of the human heme oxygenase gene. Carcinogenesis 13:227-232

18. Dennery PA, Wong HE, Sridhar KJ, Rodgers PA, Sim JE, Spitz DR 1996 Differences in basal and hyperoxia-associated $\mathrm{HO}$ expression in oxidant-resistant hamster fibroblasts. Am J Physiol 271:L672-L679 
19. Lee PJ, Alam J, Sylvester SL, Inamdar N, Otterbein L, Choi AM 1996 Regulation of heme oxygenase-1 expression in vivo and in vitro in hyperoxic lung injury. Am J Respir Cell Mol Biol 14:556-568

20. Applegate LA, Luscher P, Tyrrell RM 1991 Induction of heme oxygenase: a general response to oxidant stress in cultured mammalian cells. Cancer Res 51:974-978

21. Gutteridge JM 1982 Fate of oxygen free radicals in extracellular fluids. Biochem Soc Trans 10:72-73

22. Dennery PA, Spitz DR, Yang G, Tatarov A, Lee CS, Shegog ML, Poss KD 1998 Oxygen toxicity and iron accumulation in the lungs of mice lacking heme oxygenase-2. J Clin Invest 101:1001-1011

23. Dani C, Martelli E, Bertini G, Pezzati M, Filippi L, Rossetti M, Rizzati G, Rubaltelli FF 2003 Plasma bilirubin level and oxidative stress in preterm infants. Arch Dis Child Fetal Neonatal Ed 88:F119-F123

24. Chessex P, Laborie S, Lavoie JC, Rouleau T 2001 Photoprotection of solutions of parenteral nutrition decreases the infusion load as well as the urinary excretion of peroxides in premature infants. Semin Perinatol 25:55-59

25. Rubaltelli FF, Glenn RG, Loskamp N, Modi N, Roth-Kleiner M, Sender A, Vert P 2001 Transcutaneous bilirubin measurement: a multicenter evaluation of a new device. Pediatrics 107:1264-1271

26. Mates JM 2000 Effects of antioxidant enzymes in the molecular control of reactive oxygen species toxicology. Toxicology 153:83-104

27. Buonocore G, Perrone S, Longini M, Terzuoli L, Bracci R 2000 Total hydroperoxide and advanced oxidation protein products in preterm hypoxic babies. Pediatr Res 47:221-224

28. Ellman GL 1959 Tissue sulfhydryl groups. Arch Biochem Biophys 82:70-77

29. Kime R, Gibson A, Yong W, Hider R, Powers H 1996 Chromatographic method for the determination of non-transferrin-bound iron suitable for use on the plasma and bronchoalveolar lavage fluid of preterm babies. Clin Sci (Lond) 91:633-638

30. McCord JM, Fridovich I 1969 Superoxide dismutase. An enzymatic function for erythrocuprein (hemocuprein). J Biol Chem 244:6049-6055

31. Pauly TH, Smith M, Gillespie M 1991 Bilirubin as an antioxidant: effect group B streptococci-induced pulmonary hypertension in infant piglets. Biol Neonate 60:320-326

32. Lamb NJ, Quinlan GJ, Mumby S, Evans TW, Gutteridge JM 1999 Haem oxygenase shows pro-oxidant activity in microsomal and cellular systems: implication for the release of low-molecular-mass iron. Biochem J 344:153-158

33. Lautier D, Luscher P, Tyrrell RM 1992 Endogenous glutathione levels modulate both constitutive and UVA radiation/hydrogen peroxide inducible expression of the human heme oxygenase gene. Carcinogenesis 13:227-232
34. Lee PJ, Alam J, Sylvester SL, Inamdar N, Otterbein L, Choi AM 1996 Regulation of heme oxygenase-1 expression in vivo and in vitro in hyperoxic lung injury. Am J Respir Cell Mol Biol 14:556-568

35. Dennery PA, Spitz DR, Yang G, Tatarov A, Lee CS, Shegog ML, Poss KD 1998 Oxygen toxicity and iron accumulation in the lungs of mice lacking heme oxygenase-2. J Clin Invest 101:1001-1011

36. Dennery Pa, Sridhar KJ, Lee CS, Wong HE, Shokoohi V, Rodgers PA, Spitz DR 1997 Heme oxygenase-mediated resistance to oxygen toxicity in hamster fibroblasts. J Biol Chem 272:14937-14942

37. Suttner DM, Sridhar K, Le CS, Tomura T, Hansen TN, Dennery PA 1999 Protective effects of transient HO-1 overexpression on susceptibility to oxygen toxicity in lung cells. Am J Physiol 276:L443-L451

38. Dennery PA 2000 Regulation and role of heme oxygenase in oxidative injury. Curr Top Cell Regul 36:181-199

39. Motterlini R, Foresti F, Vandegriff K, Intaglietta M, Winslow RM 1995 Oxidative stress response in vascular endothelial cells exposed to acellular hemoglobin solutions. Am J Physiol 269:H648-H655

40. Ferris CD, Jaffrey SR, Sawa A, Takahashi M, Brady SD, Barrow RK, Tysoe SA Wolosker H, Baranano DE, Dore S, Poss KD, Snyder SH 1999 Haem oxygenase-1 prevent cell death by regulating cellular iron. Nat Cell Biol 3:152-157

41. Samb A, Taillè C, Almolki A, Megret J, Staddon JM, Aubier M, Boczkowski J 2002 Heme oxygenase modulates oxidant-signaled airway smooth muscle contractility: role of bilirubin. Am J Physiol 283:L596-L603

42. Ndisang JF, Masini E, Mannaioni PF, Wang R 2002 Carbon monoxide and cardiovascular inflammation. In: Wong R (ed) Carbon Monoxide and Cardiovascular Functions. CRC Press, Boca Raton, pp 165-180

43. Mirabella C, Baronti R, Berni LA, Gai P, Ndisang JF, Masini E, Mannaioni PF 1999 Hemin and carbon monoxide modulate the immunological response of human basophils. Int Arch Allergy Immunol 118:259-260

44. Di Bello MG, Berni L, Gai P, Mirabella C, Ndisang JF, Masini E, Bani Sacchi T, Mannaioni PF 1998 A regulatory role of carbon monoxide in mast cell function. Inflamm Res 1:S7-S8

45. Otterbein LE, Bach FH, Alam J, Soares M, Tao Lu H, Wysk M, Davis RJ, Flavell RA, Choi AM 2000 Carbon monoxide has anti-inflammatory effects involving the mitogen-activated protein kinase pathway. Nat Med 6:422-428 